\title{
Informação e produção de sentido: a integração da categoria recepção no processo documentário-informacional
}

\author{
Marilda Lopes Ginez de Lara ${ }^{1}$ \\ Maria de Fátima Gonçalves Moreira Tálamo²
}

\section{Resumo}

As tecnologias da informação e da comunicação ainda não respondem integralmente às questões do acesso à informação semântica, razão pela qual continuam pertinentes os investimentos em metodologias de organização prévia da informação. Ao comparar a sociedade da informação com a sociedade de massa emerge a importância da categoria da recepção. Como inserir tal categoria nos procedimentos documentários, como entendê-la no âmbito da circulação social da informação e do conhecimento são indagações recorrentes que apresentam, no entanto, avanços tímidos no que tange às respostas dadas. O presente trabalho propõe a integração da categoria da recepção no processo documentário através da noção de interação, substituindo a idéia de usuário ideal pela de sujeito social. Pressupõe-se que um sistema de recuperação da informação apresente-se como máquina produtora de sentido, valendo-se de linguagem documentária que contemple invariavelmente a oferta de opções, segundo as especificidades qualificadas das demandas informacionais.

Palavras-chaves: Recepção; sociedade de massas; linguagem documentária; processos documentários; comunicação documentária; lingüística documentária; terminologia

\begin{abstract}
Information and communication technologies are still not enough to give full answer to the matter of access to semantic information. That is why works towards methodologies of previous organization of information remain standing. The importance of the concept of reception emerges when we compare information society to mass society. Are recurrent matters the ones of how to observe such category (reception) in the documentary procedures, how to understand it within the social flow of information and knowledge, but the answers have been shy. The present work intends to integrate the category of reception in the documentary procedure through the notion of interaction, replacing the idea of ideal user for the one of social subject. We presupose that a information recovery system presents itself as a meaning production machine, taking into account a documentary language that includes options according to qualified specificities of informational demands.
\end{abstract}

Keywords: Reception ; mass societies; documentary language; documentary procedures; documentary comunication; documentary linguistics; terminology. 


\section{Introdução}

As tecnologias da informação e da comunicação têm exercido profunda influência sobre a produção, a circulação e a recepção de informações. Com a web e a oportunidade da palavra conferida, ao menos teoricamente, a um maior número de pessoas, tem-se, em contrapartida, um aumento exponencial da informação em uma multiplicidade de formas de expressão. Se de um lado aumentam as chances de acesso, de outro, tem-se o problema da seleção que deve empreender o receptor face ao universo disponível.

O papel da Ciência da Informação na situação referida se relaciona à construção e disponibilização de 'filtros' para orientar a busca e a recuperação, inspirados largamente na garantia literária, com recurso à terminologia de área, e na garantia de uso, ainda incipiente em termos de metodologias eficientes para sua elaboração. Como afirma Gutiérrez, "Evadir-nos da classificação, ou afastarmo-nos, mesmo que um passo, é tão utópico como querer fugir da linguagem ou do pensamento" (Garcia Gutiérrez, 2006). O problema , se relaciona, nesse sentido, à escolha dos parâmetros de organização da informação e, principalmente, ao grau de adequação dos mesmos para viabilizar sua circulação, acesso e uso.

A simples rejeição ao uso de modelos universais de classificação não é suficiente para garantir ótimas distribuição e apropriação da informação. Por outro lado, a integração do componente 'recepção' nos fluxos sociais da informação ainda permanece bastante vinculada a estruturas de codificação da informação, ignorando que o acesso e o uso da informação tem como ator o sujeito real, territorializado.

\section{A Categoria recepção}

O conceito de sociedade de massa é importante para o entendimento da importância dos filtros sociais para o exercício da competência informacional na sociedade da informação.

O termo sociedade de massa é utilizado com diferentes acepções, sinalizando variantes de sentido que devem ser identificadas. Para o pensamento político, a sociedade de massa é conseqüência da crescente industrialização, da revolução dos transportes e do comércio e da difusão de valores abstratos de igualdade e de liberdade (Wolf, 2003) . No seu conjunto, tais processos conduzem a uma homogeneização e indistinção que enfraquecem a conectividade da sociedade. Isso se expressa de maneira clara na expressão "alienação das massas".

Ortega y Gasset (apud Wolf, 2003) considerava, já nos anos 30 do século passado, que a ascensão das massas subvertia o que era singular, individual, "tudo o que é classificado e selecionado". A massa encontra-se apoiada apenas na semelhança, naquilo que os indivíduos têm em comum, o que, não raro, pode ser sintetizado na existência de uma única idéia. Nesse sentido, a sociedade de massa define-se como uma ordem 
social que não possui estrutura organizativa, constituída por um conjunto homogêneo de indivíduos, indiferenciáveis, mesmo que provenham de ambientes diferentes e heterogêneos.

Sobre apenas o que é comum, as pessoas não exercem influências recíprocas. Na sociedade de massa os indivíduos encontram-se atomizados, anônimos e isolados, subjugados por conteúdos e mensagens veiculados pelos media. Entende-se habitualmente, por esse motivo, que os media têm um efeito uniformizador e manipulador, com o objetivo de captar audiência e não o de implementar um universo de alternativas, como se supõe que seja uma das funções das TICs. De forma direta os media, cujos processos de mediatização operam com sentido único, intervêm muito mais na dimensão afetiva de conteúdos do que no seu plano cognitivo.

A cultura de massa, como conseqüência, desenvolve-se não só sobre a assimetria entre a emissão e a recepção mas também ao largo de relações sócio-culturais. Dito de outro modo, o efeito da comunicação, no contexto massivo, está mais para uma reação do que para uma produção efetiva de sentido levada a cabo pela recepção. De fato, o termo mais apropriado seria "recepção de massa" já que nessas condições apenas o destinador é ativo e intencional.

A superação dessa visão de sociedade de massa passa a ser discutida quando os estudos da comunicação associam a recepção a uma prática. Consideram-se com esses estudos que os efeitos dos meios massivos não se resumem à manipulação ou à persuasão. Sob a ótica da prática, a influência da comunicação encontra-se subsumida pelo papel das relações comunitárias.

Embora o papel social da Ciência da Informação não se encontre associado diretamente às políticas massivas de distribuição da informação, a performance do seu sujeito-usuário está bastante influenciada pelo contexto massivo. Para além disso, embora não o faça de modo afirmativo, a atividade documentária reproduz parte desse modelo ao reconhecer a produção como matriz do processo comunicacional. Não é suficiente que se anuncie a importância, na sociedade contemporânea, do valor social da informação na ausência de procedimentos que o atualize de forma efetiva. Por isso é necessário empreender a busca de entendimento da categoria da recepção para mobilizar as políticas de informação.

Compreende-se, hoje, a emissão e a recepção como construções interdependentes que colocam em jogo a interpretação. Esse entendimento é resultante de um longo percurso de discussões e teorias que perpassam várias áreas do conhecimento: Filosofia, Lingüística, Comunicações, Ciências Sociais de um modo geral.

Na perspectiva dos estudos sociológicos, determinadas vertentes de pensamento, muitas vezes reunidas sob o título de Teoria da Ação, relacionam cultura e sociedade. Talcott Parsons, por exemplo, transpõe o sentido do ator social da esfera individual, antes dominante, para a esfera coletiva, compreendendo a ação social como forma estruturante da cultura e da sociedade tendo como base da comunicação interpessoal. Já Bourdieu questiona a antinomia entre estruturas da sociedade e ação, entre sociedade e indivíduo, a partir do conceito de habitus, um sistema de disposições que integra a experiência passada e assegura a coerência entre o individual e coletivo (Mattelart \& Mattelart, 2002). 
Abordagens etnometodológicas falam da 'teoria da estruturação' (como em Giddens) propondo imbricação entre práticas e estrutura (Mattelart \& Matterlart, 2002); Blumer compreende o significado como produto de interpretação consciente das interações na vida social (Ferin, 2002).

$\mathrm{Na}$ confluência entre a Filosofia e os estudos da Linguagem, a pragmática lingüística, desde a 'teoria dos atos da fala' (Austin), reabilita a condição do sujeito como ator do discurso, promovendo a função performativa da linguagem, além da descritiva. Com o II Wittgenstein, a noção de 'jogos de linguagem' ressalta o uso prático que dela se faz no cotidiano. A linguagem em uso é elemento da interação social, integrada em 'atividades ou formas de vida'. A virada lingüística influenciou a proposta de uma sociologia crítica do 'agir comunicativo' de Habermas, que advoga ações orientadas para a intercompreensão e o consenso. Ao associar ação e interação, destacam-se as trocas simbólicas e os contextos lingüísticos onde ocorrem, evidenciando o caráter intersubjetivo do discurso e a compreeensão dos atores sociais como produto dos processos de socialização que os formam.

As teorias da comunicação recentes se definem, na maior parte das vezes, por remissão ao conjunto dos estudos lingüísticos, filosóficos e lingüísticos. Destacam-se nos dias de hoje as referências aos Estudos Culturais que, primeiramente, se preocuparam em estudar a interpretação segundo relações de classe, priorizando o caráter ideológico da cultura (Thompson), e, em seguida, a função mediadora da linguagem na produção do sentido e da significação, ou ainda, enfatizando o papel ativo dos indivíduos frente às mensagens (Stuart Hall). Na América Latina, Canclini e Martin Barbero investem fortemente nas pesquisas de recepção acentuando a importância da mediação e das relações de resistência dos sujeitos frente às mídias (Ferin, 2002)

$\mathrm{Na}$ Lingüística e nos estudos da linguagem, as questões da recepção são primeiramente propostas pelas teorias da enunciação. Benveniste analisa a subjetividade na língua enquanto ação do produtor do enunciado. Mais tarde, Ducrot propõe-se a rever a noção de combinatória semântica, sugerindo que ela é explorada pelos sujeitos falantes para organização das relações intersubjetivas no diálogo (Ducrot, citado por Paveau \& Sarfati, 2006). No âmbito das propostas estruturalistas de análise do discurso, o autor enfatiza o caráter lingüístico do ato de argumentar, inserindo a argumentatividade no interior do próprio sistema da língua (Fávero \& Koch, 1998).

Na Lingüística Textual, vários pesquisadores sugerem a incorporação da pragmática nos estudos lingüísticos. Schmidt prioriza a competência comunicativa, mais do que a textual, quando vê no ato de comunicação uma forma específica de interação social. Pêcheux ressalta os aspectos ideológicos e culturais, além dos lingüísticos e discursivos, e põe em evidência a questão da subjetividade ao discutir o efeito-leitor. Van Dijk fala das funções conversacionais, interacionais e cognitivas do macroato. Petöfi inclui, em sua Teoria do Texto, além dos componentes textuais, outros componentes relacionados a condições externas de produção, recepção e interpretação. 
O pensamento pragmático atinge, também, a Ciência da Informação, embora apenas recentemente. Antes disso, a Biblioteconomia privilegiou a emissão, focando prioritariamente a organização dos acervos. Sob a ótica cognitiva, em seguida, foram ressaltadas as operações individuais de acesso à informação. Nos dias de hoje as abordagens tendem a conjugar as referências individuais e coletivas, observando os contextos sócioeconômicos e culturais onde se dão as ações de informação (Capurro, 2003). As tendências contemporâneas relacionadas à discussão não são, no entanto, homogêneas.

O que foi dito é suficiente para colocar em relevo o fato de que a produção de sentido não é atividade exclusiva da emissão. A interação recompõe a simetria entre os pólos da cadeia comunicacional, afirmando que os papéis de codificador e de decodificador são complexos.

\section{A categoria recepção nas linguagens documentárias}

Em face ao exposto, pode-se fazer uma breve análise dos instrumentos construídos pela Documentação, genericamente reunidos sob a denominação linguagens documentárias.

Os sistemas classificatórios, urdidos no início do séc. XX, tinham sua justificativa na priorização das funções de guarda e preservação, mais do que na circulação, pautando-se em estruturas universais (ocidentais) de organização do conhecimento. Sistemas especializados, por seu turno, procuraram garantir o atendimento às necessidades de grupos restritos, circunscritos a empresas e áreas técnicas principalmente ligadas à indústria. Os tesauros, instrumentos mais complexos que melhor observam os aspectos semânticos, também não apresentaram (e ainda nem sempre apresentam) modos consistentes de trabalhar as áreas temáticas visadas e, menos ainda, vínculos de significação com os seus usuários imaginados. A introdução de referenciais da Lingüística para a elaboração dos tesauros representou um avanço considerável, mas a sua estruturação tem privilegiado mais a organização do sistema em si, do que seu uso efetivo. Exemplo disso são os tesauros que, embora tenham sido produzidos a partir da noção de associação de idéias, numa referência ao Tesauro de Roget, têm como elemento central a rede paradigmática dos descritores. O relacionamento entre os termos, teoricamente um recurso para a sintagmatização, caracteriza-se mais pela função de adjetivação e reforço semântico dos descritores próximos, do que meio para a criação de novos conceitos relacionados por coordenação.

Pelo exposto, verifica-se que a categoria dominante nos instrumentos de classificação e de indexação as linguagens documentárias - foi e continua sendo a emissão, alienando dos instrumentos qualquer referência à participação do usuário na construção das mensagens documentárias. Tem-se então a reiteração do usuário formado pela mídia massiva. Reforça tal afirmação o argumento de que a atividade documentária, na maior parte das vezes, supõe que os conteúdos sejam objetivos e interpretáveis de modo homogêneo. A noção de conteúdo, embora cara à Documentação é bastante frágil, porque depende de um processo arbitrário de seleção 
que geralmente associa a representação à objetividade e à verdade, desconsiderando a natureza dialógica da comunicação. Com as TIC's, a situação se agrava, uma vez que elas permitem a realização técnica da dialogia.

Como inserir tal categoria nos procedimentos documentários, como entendê-la no âmbito da circulação social da informação e do conhecimento são indagações recorrentes que apresentam, no entanto, avanços tímidos no que tange às respostas dadas.

Sob a ótica da dialogia, a recepção é o lugar da interpretação. Ao contrário do que ocorre na comunicação de massa, os fluxos de informação institucionalizada dispõem de alternativas para o exercício da seleção. Nesse sentido, entende-se o conteúdo das mensagens documentárias como interpretações desenvolvidas a partir do quadro das referências simbólicas e dos sentidos sociais da informação.

Semelhante proposta integra parcialmente a noção de interação à linguagem documentária corelacionando referências de valor dos quadros da emissão e da recepção. Parte-se do pressuposto de que em sistemas informacionais pré-organizados a linguagem documentária deve ser um instrumento a partir do qual são realizadas as trocas de bens simbólicos que mobilizam, simultaneamente, dados cognitivos e sócioculturais. A integração da categoria recepção relaciona, desse modo, informação e linguagem.

Posto que as operações documentárias são construídas visando o sujeito social e que a interação se realiza a partir de valores expressos em linguagem, busca-se ancorar os mecanismos de recuperação em referências validadas socialmente. Esta é a condição para que efetivamente as trocas aconteçam e garantam o sucesso da comunicação documentária e da interpretação. Tais mecanismos não visam os sujeitos na sua individualidade, mas os grupos que compartilham interesses e linguagem, mesmo porque a Documentação, como prática social, não tem condições de trabalhar com referências individuais dos usuários, que mobilizariam outros elementos, dentre eles, os psicológicos.

Os investimentos teóricos brasileiros que buscam contemplar a validação social dos termos utilizados na organização e recuperação da informação inicialmente procuraram verificar os aspectos relacionados à língua tratada pela metalíngua, ou linguagem documentária. Posteriormente, foi proposta a separação de procedimentos metodológicos de análise documentária e de construção de linguagens documentárias, investindo-se em metodologias próprias para a elaboração dos instrumentos de intermediação (García Gutiérrez, 1990; Tálamo et al., 1992; Lara, 1993, dentre outros). Em seguida, passou-se a integrar as referências terminológicas, estabelecendo-se um diálogo com o campo de estudos da Terminologia (Sager, 1990; Cabré, 1993, dentre outros). Visto que a Terminologia trabalha com os discursos, a Documentação recupera indiretamente, por essa via, as referências de uso concreto dos termos, alterando a situação metodológica anterior que reduzia o resultado da coleta de termos a unidades isoladas dos discursos de origem (Tálamo et al., 1992; Lara, 1993; 1999; dentre outros). O uso de referências terminológicas foi tomado como base para as hipóteses de organização das linguagens documentárias (Tálamo, 1997; Lara, 1999). 
Na primeira década deste século, nos estudos brasileiros acima referidos, foram questionados os princípios da linha terminológica clássica que restringiam o papel da linguagem restrito à denominação dos conceitos e que adotavam uma posição prescritiva e essencialmente normativa dos procedimentos terminológicos. Essa posição representou um alinhamento às novas propostas da Terminologia de cunho comunicativo e social (Lara, 2004; 2006). Essa nova visada permite observar a variação conceitual e designacional, sendo mais sensível às condições efetivas de uso dos termos e da formulação dos conceitos no interior da linguagem.

Pode-se afirmar, assim, que os esforços teóricos dos investimentos na linguagem documentária têm se voltado à preocupação de incluir, nelas, vínculos de significação e de adesão com seus usuários. Seu resultado, no entanto, não pode ser caracterizado, ainda, de modo a contemplar a recepção. Ele apenas procura integrar referências consistentes de uso nos processos de codificação que caracterizam a produção da linguagem documentária.

\section{As pesquisas contemporâneas da categoria na ciência da informação}

Integrar a categoria recepção na Documentação, via noção de interação, significa mobilizar um conceito mais amplo de linguagem nas práticas documentárias. De um lado, trata-se de verificar os limites de uma linguagem construída e de sua aplicação nos processos de produção documentária. Tal limite se refere à incorporação, na codificação, dos dados das possibilidades de recepção supondo características das comunidades de usuário. Princípios de compartilhamento estão na base dos processos comunicacionais em ambientes documentários. De outro, conforme sugere González de Gómez (2004), coloca-se a questão dos dispositivos de informação não-formalizados por regras sistêmicas, que implicaria em observar a forma como as pessoas definem, criam e buscam a informação, como as condições que intervêm no acesso. Ou se trataria de "cruzar as diferentes linhas de indagação", conforme sua proposta.

Na primeira proposta, considera-se que usuários e linguagens não são homogêneos. Nos limites da linguagem construída, a interação via instrumento de comunicação em ambientes documentários deve se desenvolver a partir de um conjunto de informações que envolvem arranjos de significação particulares e mecanismos que permitam o desenvolvimento semiótico dos processos de interpretação. Na segunda proposta, ao menos teoricamente, pode-se supor que um investimento na pragmática lingüística, em particular nas teorias contemporâneas de lingüística textual, permitiriam subsidiar a Documentação no desenvolvimento de mecanismos de interação com os usuários. Isso implicaria, inicialmente, rever noção de texto como unidade acabada, substituindo-a pela noção de lugar de interação entre atores sociais. Demandaria considerar, no âmbito da atividade documentária, a possibilidade de dispor de instrumental tecnológico que sustentasse não apenas exatamente a organização da informação, mas a apresentação de um conjunto de elementos exteriores 
ao texto (de outro modo estaríamos falando em processamento em linguagem natural, que não é o caso), a partir dos quais fosse possível viabilizar as relações de construção interacional dos sentidos. Temas como referenciação, inferenciação, acesso a conhecimentos prévios, ao lado de questões relativas aos gêneros textuais (Koch, 2006), poderiam ser mobilizadas para indicar a relevância dos textos reunidos no sistema informacional para os objetivos e necessidades dos usuários. Tal empreendimento, no entanto, é ainda uma possibilidade teórica.

\section{Conclusão}

Em larga medida a visão tradicional da Documentação reflete a importância atribuída à fonte emissora. Com isso estabelece-se um desequilíbrio entre os componentes do processo de transmissão de modo a comprometer a relação entre a informação e o conhecimento, embora exista dificuldade no reconhecimento das assimetrias. Entre essas, destacam-se os papéis isolados do emissor e receptor.

Esforços para definir a natureza da emissão documentária vêm sendo empreendidos através do recurso à noção de instituição. Acredita-se, nesse sentido, que a produção da informação reflete os objetivos e a missão das instituições que a desenvolve. Assim a natureza da informação é institucional. No que tange aos fluxos - processos de circulação e acesso - considera-se que exercem a função social de abastecer a sociedade com alternativas para uso. O fluxo social da informação, no sentido que lhe é aqui atribuído, funciona como mensagem.

Os estudos acerca da forma da mensagem mais adequada para integrar os fluxos sociais de informação ainda são embrionários. As inúmeras formas de mensagem encontradas na web indicam que a procura por uma resposta factível persiste, mesmo que seja de forma velada. No entanto poucos estudos sobre a eficácia da estrutura das mensagens atentam para a importância de algumas características dos usuários que sinalizam para o modo de interação possível. De fato, acredita-se que uma vez disponível a informação e concebidos os usuários como um conjunto de classes etárias, de sexo, de profissão, etc... resolve-se a questão dos fluxos sociais de informação. Esse é o contexto da cultura de massa e não o da cultura da informação assentado no valor do conhecimento e da informação. É preciso ir além e buscar no modo pelos quais os vários segmentos sociais desenvolvem as relações informais e suas práticas elementos para a composição de filtros sociais mais integrativos. Nesse sentido as formas de acesso cognitivo à informação ganham destaque, uma vez que exigem a construção de redes, metáforas das interações que vivem. Jamais se ignorou que o usuário vivesse em grupos com interesses formulados de forma específica, com fontes de informação próprias , etc... Supunha-se apenas que nada disso tinha importância para o funcionamento dos fluxos de informação. Hoje se discute como integrar esses componentes ao processo documentário, já que nenhum de seus elementos isolados garante o uso efetivo da informação. 


\section{Referências bibliográficas}

CABRÉ, M.T. (1993). La terminología: teoría, metodologia, aplicaciones. Barcelona : Ed. Antártida ; Empúries.

CAPURRO, R. (2003). Epistemologia y Ciencia de la Información. Conferencia presentada em el V Encontro

Nacional de Pesquisa e Pós-Graduação em Ciência da Informação - ENANCIB, Belo Horizonte, nov.

Consulté le: www.capurro.de/enancib.htm.

FÁVERO, L.L. \& KOCH, I.G.V. (1998). Lingüística textual: introdução. 4.ed. São Paulo: Cortez.

FERIN, I. (2002). Comunicação e culturas do quotidiano. Lisboa: Quimera Ed. Garcia Guitiérrez, A (2006).

Cientificamente favelados: uma visão crítica do conhecimento a partir da epistemografia.

TransInformação, Campinas, v.18, n.2, p.103-112. Consulté le

http://revistas.puc-campinas.edu.br/transinfo/viewissue.php?id=13\#Artigos

GONZALEZ DE GÓMEZ, M. N. (2004). Novas fronteiras tecnológicas das ações de informação: questões e abordagens. Ciência da Informação, Brasília, v. 33, n. 1, p. 55-67. Consulté le http://www.ibict.br/cionline/viewarticle.php?id=90\&layout=abstract

KOCH, I.G.V. Introdução à lingüística textual. São Paulo: Martins Fontes, 2006.

LARA, M. L. G. Diferenças conceituais sobre termos e definições e implicações na organização da linguagem documentária. Ciência da Informação, Brasília, v. 33, n. 2, p. 91-96, 2004. Consulté le http://www.ibict.br/cionline/viewissue.php?id=6\#Artigos

LARA, M. L. G. (2006) . Novas relações entre Terminologia e Ciência da Informação na perspectiva de um conceito contemporâneo da informação. Datagramazero (Rio de Janeiro), v. 7, p. 2. Consulté le http://www.dgz.org.br/ago06/F_I_art.htm

LARA, M. L. G. A representação documentária: em jogo a significação. São Paulo: ECA/USP, 1993 (Dissertação de Mestrado em Ciências da Comunicação)

LARA, M. L. G. Representação e linguagens documentárias: bases teórico-metodológicas. São Paulo, ECA/USP, 1999. (Tese de Doutorado em Ciências da Comunicação).

MATTELART, A. \& MATTELART, M. (2002). História das teorias da comunicação. Trad. Luiz Paulo Rouanet. São Paulo: Loyola.

PAVEAU, M.-A. \& SARFATI, G.-E. (2006). As grandes teorias da Lingüística: da gramática comparada à pragmática. Trad. de M.R. Gregolin et al. São Carlos: Claraluz, p.63-84.

SAGER, J.C. (1990). A practial course in terminlogy processing. Amsterdam; Philadelphia: John Benjamins. TÁLAMO, M. F. G. M. (1997). Linguagem Documentária. São Paulo: APB- Associação Paulista de Bibliotecários, 1997. v. 1. 25 p. 
TÁLAMO, M. F. M.; Lara, M. L. G.; Kobashi, N. Y. . Contribuição da terminologia para a elaboração de tesauros. Ciência da Informação, Brasília, v. 21, n. 3, p. 197-200, 1992.

WOLF, M. (2003). Teorias da Comunicação. Lisboa: Editorial Presença, 2003.

\footnotetext{
${ }^{1}$ Universidade de São Paulo

Escola de Comunicações e Artes

Depto. de Biblioteconomia e Documentação

Programa de Pós-Graduação em Ciência da Informação

Av. Prof. Lúcio Martins Rodrigues, 443, 20.

São Paulo - Brasil - CEP 05508-900

${ }^{2}$ Pontifícia Universidade Católica de Campinas

Programa de Pós-Graduação em Ciência da Informação

Rua Marechal Deodoro, $\mathrm{n}^{\circ} 1099$

Campinas - SP - CEP: 13010-920
} 